ESPAÇO TEMATTICO: SERVIÇO SOCIAL: GÊNERO, RAÇA/ETNIA, GERAÇÕES E SEXUALIDADE

\title{
O feminicídio e a legislação brasileira
}

\author{
Suzanny Mara Jobim de Souza ${ }^{1}$ \\ https://orcid.org/0000-0001-6710-5921 \\ ${ }^{1}$ Universidade Federal da Bahia, Instituto de Psicologia, Salvador, BA, Brasil
}

\section{O feminicídio e a legislação brasileira}

Resumo: Este ensaio avalia as consequências do dissenso entre as noções de gênero e sexo nos estudos de especialistas, tendo em vista o combate ao feminicídio no Brasil. Enquanto a legislação reconhece a noção de sexo para definição do crime, o Executivo, em suas políticas públicas, trabalha com a noção de gênero. O objetivo é analisar a origem do conceito de feminicídio, a identidade de seus perpetradores, a dissensão dos conceitos de sexo e gênero e a dualidade na legislação e nas políticas públicas brasileiras. Divide-se em três partes, cada seção analisando os diferentes conteúdos do objetivo principal. Em seus resultados, concluiu-se pela emergência da noção de gênero na definição de feminicídio como forma de empoderamento feminino.

Palavras-chave: Feminicídio. Gênero. Políticas públicas. Feminismo.

\section{Femicide and Brazilian laws}

Abstract: This essay evaluates the consequences of the disagreement between notions of gender and sex in the studies of specialists, with a view to combating femicide in Brazil. While the legislation recognizes the notion of sex to define a crime, the Executive branch works with the notion of gender in the public policies. The objective is to analyze the origin of the concept of femicide, the identity of its perpetrators, the dissension of the concepts of sex and gender and the duality in Brazilian public policies and laws. The essay is divided into three parts, each section analyzing the different contents of the main objective. The results conclude that the emergence of the notion of gender in the definition of femicide is a form of female empowerment.

Keywords: Femicide. Genre. Public policy. Feminism.

Recebido em 09.01.2018. Aprovado em 25.05.2018. Revisado em 26.06.2018.

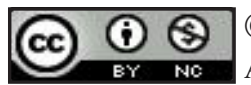

(C) O(s) Autor(es). 2018 Acesso Aberto Esta obra está licenciada sob os termos da Licença Creative Commons

Atribuição-NãoComercial 4.0 Internacional (https://creativecommons.org/licenses/by-nc/4.0/deed.pt_BR), que permite copiar, distribuir e reproduzir em qualquer meio, bem como adaptar, transformar e criar a partir deste material, desde que para fins não comerciais e que você forneça o devido crédito aos autores e a fonte, insira um link para a Licença Creative Commons e indique se mudanças foram feitas. 


\section{Introdução}

Este ensaio trata do feminicídio e a forma dualista com que é admitido na legislação brasileira. Teve a seguinte problematização: Com que clareza o Legislativo e Executivo tratam o tema no Brasil? A delimitação ficou por conta da inserção das noções de sexo e gênero na legislação e nas políticas públicas no Brasil. A escolha do tema se justifica em razão dos conceitos que enformam o combate a esse tipo de crime contra a mulher e o continuum de agressões que culminam no feminicídio no Brasil. Achamos que a discussão do tema ajuda a compreender melhor a atitude das autoridades e da sociedade brasileira diante da violência da mais extremada forma de agressão contra o gênero feminino. Selecionaram-se os seguintes objetivos: analisar o conceito de feminicídio e suas noções divergentes, como gendercide, femicide e femicídio; avaliar as contribuições dos estudos sobre o tema no mundo e o impacto de massacres de mulheres para a luta contra a violação do direito à vida; identificar a dualidade das noções de sexo e gênero, o primeiro admitido na legislação brasileira e o segundo nas políticas públicas do poder executivo.

Como metodologia, buscou-se a análise dos diferentes conceitos de feminicídio e sua origem nas últimas décadas do século passado, a análise dos impactos de mortes violentas perpetradas por questões de gênero, $o$ questionamentos entre feministas sobre a questão cultural com que se firma a noção de gênero e sexo e, por fim, a dualidade que esse questionamento acaba provocando no combate a esse tipo de violência contra a mulher, para imposição de um status quo do gênero masculino numa sociedade patriarcal. O recorte teórico ficou por conta dos estudos sobre a origem e configuração das diferentes noções de feminicídio, a identidade dos perpetradores desse crime e a posição da justiça brasileira, assim como dos poderes legislativo e executivo. A perspectiva teórico-metodológica ganha sentido na medida em que avalia o conceito mais amplo para feminicídio, as dissensões sobre a culturalidade imposta à questão do sexo biológico e gênero, no seio do próprio movimento feminista, e as consequências dessa dubiedade na legislação e no combate ao crime. O ensaio está dividido em três partes: na primeira seção analisou-se a melhor conceituação para feminicídio, aceitando-se aquela mais ampla, que trata da omissão do Estado; a segunda seção analisou a sociedade patriarcal e o continuum de agressões e violências que culminam no feminicídio; e a terceira questionou as dissensões existentes sobre a própria definição de gênero e sua dualidade em oposição ao sexo, desencontro que atinge diretamente o combate ao crime efetuado pelo Estado.

\section{Diferentes nomes para uma mesma violação do direito à vida}

Gendercide, femicide, femicídio ou feminicídio são os nomes surgidos nas últimas décadas do século passado para definir um mesmo fenômeno, o assassinato de mulheres por questões de gênero. Mas cada um deles traz em si próprio uma diferença que é preciso destacar, levando-se em conta os propósitos desta pesquisa. Warren (1985) cunhou o termo gendercide pela primeira vez, referindo-se ao extermínio deliberado de mulheres, através de todo tipo de violência, entre eles o infanticídio e a seleção do sexo. Ela chega a comparar o genericídio com o genocídio, com a diferença de que um trata de raça enquanto o outro relaciona-se ao sexo, mas a finalidade é a mesma. Warren (1985) está mais preocupada em denunciar a seleção sexual como forma de gendercide, principalmente com o uso crescente da tecnologia.

No século passado, registra-se um número de mulheres mortas comparado ao número de homens em duas guerras mundiais, somente pelo fato de terem nascido com o sexo feminino. Para Grech e Mamo (2014), o patriarcado está na base de poder diferencial entre homens e mulheres, sob o qual estas são as vítimas e pelo qual se busca um mundo masculinizado demograficamente. O infanticídio de indivíduos do sexo feminino tem uma longa tradição em países da Ásia, como a China. A prática era expor os bebês aos elementos da natureza ou abandoná-los nas ruas da cidade ou nos arredores. A modernidade acabou com essa prática, pois oferece tecnologia para determinar o sexo antes do nascimento, por meio de técnicas pré-natais. Os esforços para se apagar bebês femininos da sociedade, devido à preferência de filhos masculinos, levou ao desaparecimento de mulheres, combinado com outras práticas, como infanticídio, abuso sexual, nutrição e cuidados médicos inadequados, seleção sexual e o não registro de filhos, particularmente na Ásia, afirmam Grech e Mamo (2014).

Em virtude desses fatores, os autores apontam a morte de cerca de 200 milhões de mulheres nessa região. Pelos números das Nações Unidas, o número equivale à falta ou o sumiço de mulheres em todo o mundo simplesmente por questões de gênero. Myers (2012) aponta ofemicide como correlato para gendercide, pelos mesmos motivos, a morte em massa de mulheres pelo fator da seleção através do aborto e outras motivações. Para essa autora, as mulheres mortas, baseadas apenas na questão de gênero, são vítimas de estupro, violência doméstica e crimes de honra. Elas também morrem por insuficiência de cuidados de saúde, que têm a tendência de favorecerem mais os homens na família. As discussões sobre gendercide também 
incluem a preferência em se ter apenas filhos do sexo masculino numa sociedade patriarcal. Países como o sul e o leste da Ásia são aqueles que mostram casos mais impressionantes, mas o problema é no mundo inteiro.

Ainda hoje, incluindo o Brasil, o cenário permanece o mesmo de anos de história envolvendo a perpetuação de violência contra as mulheres:

A violência contra a mulher por razões de gêneros é histórica e tem um caráter estrutural, que se perpetua devido à sua posição de subordinação na ordem sociocultural patriarcal. Tal relação de poder, baseada em padrões de dominação, controle e opressão, leva à discriminação, ao individualismo, à exploração e à criação de estereótipos, os quais são transmitidos de uma geração para outra e reproduzidos tanto no âmbito público (governo, política, religião, escolas, meios de comunicação), como no âmbito privado (família, parentes, amigos). A partir de condições históricas, são naturalizadas formas de discriminação contra a mulher e geradas práticas sociais que permitem ataques contra a sua integridade, desenvolvimento, saúde, liberdade e vida. (GEBRIM; BORGES, 2014, p. 59).

Segundo esses autores, o termo femicide, que caracteriza o assassinato de mulheres apenas por serem mulheres, foi usado pela primeira vez em 1976, no Tribunal Internacional de Crimes contra Mulheres, em Bruxelas. As soluções parecem vir de forma mais lenta nesse setor. A definição do termo só veio nos anos 1990, com Caputi e Russell (1992). Elas o definiram como sendo o assassinato de mulheres especificamente por homens motivados por ódio, desprezo, prazer ou por um sentimento de propriedade. Trata-se de um continuum de violência que estabelece uma conexão com a mais variadas formas de agressão, tais como estupro, incesto, abuso físico e emocional, assédio, pornografia, exploração sexual, esterilização, maternidade à força, dentre muitas outras. Se algumas delas resultar em morte, tem-se o femicide. Este, por sua vez, foi traduzido em países de língua hispânica como femicídio, mas não dava conta, segundo Gebrim e Borges (2014), de toda a complexidade e gravidade dos delitos. Lagarde (2006) então cunhou o termo feminicídio que passou, também no Brasil, a denominar esse tipo de crime. Ambos os termos, femicídio e feminicídio, circulam pelos países de língua latina. O segundo, entretanto, teria uma maior escala de atuação porque, segundo Lagarde (2006), destacaria não só a motivação baseada em gênero e na misoginia, mas também incluiria a ausência de políticas do Estado contra a morte de mulheres provocadas por homens em situação de poder sexual, jurídico, social, econômico, político e ideológico. Há países que dividem o feminicídio em dois tipos, um em que há relação íntima ou de convivência de casal entre homem e mulher, e aqueles que não possuíam vínculo algum, mas eram clientes em caso de exploração sexual. Decorre, enfim, de práticas atentatórias contra a vida ou a integridade das mulheres pela família, comunidade e matrimônio, e também pela ausência do Estado no combate a essa violência (GEBRIM; BORGES, 2014). Por conta disso, alguns países da América Latina, a partir de 2006, passaram a tipificar o crime de femicídio/feminicídio em suas legislações. O Brasil só viria a fazer o mesmo em 2015.

No entanto, o discurso de violência contra a mulher, do continuum ao assassinato, internacionalizava-se, indo muito além dos movimentos de feminismo. Bandeli (2017) afirma ser um problema social em todo o planeta, que continua a ser denunciado por instituições públicas, organizações internacionais, intelectuais e movimentos sociais. Para a autora, essa violência foi estabelecida em termos mundiais o que originariamente circulava entre os discursos feministas, num determinado setor, que denunciava um estado de coisas no interior de um circuito patriarcal. Segundo Bandeli (2017), o termo feminicídio, traduzido para o inglês como femicide ou feminicide, começou a circular na imprensa italiana em 2012. Jornalistas e políticos denominaram o quadro como matança, massacre e carnificina de mulheres, que sofreram violência de todo tipo e assassinato de seus parceiros. Os grupos feministas e instituições na Itália pediam reformas do sistema jurídico e ações no sentido de parar com a matança.

Uma delas, ocorrida no México, causou grande comoção e foi determinante para o aparecimento do termo feminicídio, dentro das características apontadas por Lagarde (2010), a que faz referência em outros escritos. Trata-se do massacre de 500 mulheres, a maioria de jovens moças de perfil indígena, na fronteira de El Paso e Juarez. Elas trabalhavam em manufaturas no México e mandavam dinheiro para casa. Afirma-se que foram mortas pelo único motivo de serem mulheres. Alba e Gúzman (2010) afirmam que desde o massacre de 1993 e milhares de desaparecimentos de mulheres em seguida formularam o que se pode denominar de a mais longa epidemia de violência femicida no México. Chamadas de "las inditas del sur" (ALBA; GUZMÁN, 2010, p. 2), as jovens assassinadas tinham perfil indígena, eram pobres e mais do que isto eram mulheres, a vítima preferida dessa onda de crimes que varreu o México, que aumenta o significado da misoginia de seus perpetradores. A brutalidade dos assassinatos das meninas da cidade de Juarez, no México, causa indignação e terror. Jovens de doze a vinte e três anos tiveram seus corpos desmembrados, sofreram mutilações vaginais, foram estupradas, encontradas com mãos amarradas às costas, e eram sempre do mesmo perfil: idade entre os 12 e 23 anos, cabelos escuros, pele escura, nativas, sozinhas, trabalhadoras em indústrias maquiladoras, longe 
de seus lugares de origem. Estereotipadas por uma linguagem sexista e pejorativa, eram chamadas de maquilocas, designando uma vida dupla, entre a de trabalhadora nas fábricas e a prostituição (ALBA; GÚZMAN, 2010). A matança serviu para estabelecer nacional e internacionalmente novas exigências de combate ao crime até então não reconhecido, o feminicídio.

Na opinião de especialistas como Sagot e Cabañas (2010), esse crime é uma das formas mais extremas de violência provocadas pela desigualdade de gêneros, exercida pelos homens contra mulheres, a fim de conseguir poder, controle e dominação. Incluem-se assassinatos resultantes de violência intrafamiliar e sexual. Sagot e Cabañas (2010) apresentam duas formas de feminicídio: o íntimo e o não íntimo. O primeiro ocorre nas mãos de homens com os quais a mulher mantém relações íntimas; o segundo envolve ataques sexuais contra as vítimas. Ainda existe um terceiro tipo, delineado sob a forma de um posicionamento na linha de fogo, quando a mulher ao interferir para evitar a violência morre durante a tentativa.

No Brasil, como no restante das Américas, os números de morte de mulheres por desigualdade de gêneros vêm crescendo. Meneghel e Portella (2017) mostram dados do Mapa da Violência no país. No período de 1980 a 2010 os coeficientes de mortalidade passaram de 2,3/100.000 para 4,8/100.000, num crescimento de 111 por cento. O Brasil só fica abaixo de El Salvador, Colômbia, Guatemala e Rússia, os primeiros lugares da lista.

O conceito de femicídio e feminicídio, numa cultura patriarcalista, apresenta diferenças:

O assassinato de mulheres é habitual no regime patriarcal, no qual elas estão submetidas ao controle dos homens, quer sejam maridos, familiares ou desconhecidos. As causas destes crimes não se devem a condições patológicas dos ofensores, mas ao desejo de posse das mulheres, em muitas situações culpabilizadas por não cumprirem os papéis de gênero designados pela cultura. As violências contra as mulheres compreendem um amplo leque de agressões de caráter físico, psicológico, sexual e patrimonial que ocorrem em um continuum que pode culminar com a morte por homicídio, fato que tem sido denominado de femicídio ou feminicídio. No seminário internacional realizado em 2005, Feminicídio, Política e Direito, Diana Russel considerou adequada a tradução do inglês "femicide" para o espanhol "femicídio", para evitar a feminização da palavra homicídio. Porém, autores como Marcela Lagarde diferenciam femicídio, ou assassinato de mulheres, de feminicídio, ou assassinato de mulheres pautado em gênero em contextos de negligência do Estado em relação a estas mortes, configurando crime de lesa humanidade. (MENEGHEL; PORTELLA, 2017, p. 3078-3079).

Para essas autoras, o enfrentamento se dá pelas informações fidedignas sobre a situação das mulheres que sofrem esse tipo de violência, além de se nomear, visibilizar e conceituar as mortes violentas de mulheres, além de tipificar essa espécie de crime. É preciso ainda que o Estado estabeleça seus próprios instrumentos de enfrentamento e não se omita diante do tema. Os cenários no qual ocorrem os crimes são sempre os mesmos, familiares e domésticos, principalmente, já que culturalmente as famílias de procedência patriarcal dão todo o poder ao homem. Nas relações íntimas, afirmam Meneghel e Portella (2017), as mulheres são consideradas como propriedades de maridos, namorados, companheiros e antigos companheiros.

\section{Atos de terrorismo e massacres}

Ao começarem a tratar do feminicídio, Caputi e Russell (1992) relembram um ato terrorista contra mulheres, na universidade de Montreal, em 1989. Um homem chamado Marc Lépine, armado, invadiu a universidade, separou as mulheres dos homens e abriu fogo contra elas, antes de se matar. Enquanto atirava, ele gritava, chamando-as de feministas. Morreram 14 jovens estudantes, ficaram feridas 9 mulheres e 4 homens. Junto ao corpo do atirador encontraram uma lista de nomes de proeminentes feministas canadenses. Incapaz de completar suas metas na faculdade de engenharia da Universidade de Montreal, Lépine se sentia humilhado pelas mulheres que ele definia como feministas porque elas conquistavam espaços em território masculino. Sua resposta a essa suposta humilhação foi letal e política, embora a mídia não tenha visto o massacre dessa forma. Preferiram chamá-lo de um ato de demência, para o qual não havia qualquer explicação. Para Caputi e Russell (1992), foi um ato político. Lépine odiava as mulheres, principalmente feministas. A fixação da patologia dos perpetradores de violência contra as mulheres apenas obscurece a função do controle social de seus atos. Numa sociedade racista e sexista, homens psicóticos e supostamente normais frequentemente atuam com atitudes racistas, misoginistas e homofóbicas com as quais eles cresceram e se viram legitimados.

Segundo Caputi e Russell (1992), as motivações de Lépine são evidentes e se tornam um dos mais agudos exemplos de uma criminosa ação provocada por crime de gênero. Seus assassinatos, no massacre de 
Montreal, foram crimes de ódio e tinham como alvos vítimas de crimes de gênero, não de raça, religião, etnia ou orientação sexual. Ao contrário da resposta de autoridades e da mídia, no caso desse ato de terrorismo, diferentemente, até linchamentos e pogroms são vistos como ações de motivação política. Não se perde tempo discutindo a saúde mental de seus perpetradores ou de sua experiência tensa e pessoal com afro-americanos ou com judeus. A maioria das pessoas sabe hoje que linchamentos e pogroms são formas de violência politicamente motivadas, cujos objetivos mais frequentes são para preservar a supremacia branca e gentia. Igualmente, o móvel da violência contra as mulheres, de forma consciente ou não, tem como objetivo a preservação da supremacia masculina, a primazia e o domínio do homem.

\section{Vivemos numa cultura}

feminicida. Para as autoras,

essa forma de cultura é aquela

na qual o homem é adorado.

Essa adoração provém graças

à tirania, seja ela sutil ou

aberta. Ela marcha sobre as

mentes esmagadas das

mulheres, sobre seus corpos

mortos, machucados ou

odiados, vivendo sob uma

cooptação constante, vinda de

estupradores, agressores e

assassinos.

O mesmo pode-se dizer de outra violência sexista contra as mulheres, o estupro. As autoras (CAPUTI; RUSSEL, 1992) afirmam que analistas feministas asseguram que, ao contrário do que mostram asserções mitológicas sobre o tema, o estupro não é ação frustrada de uma atração, reação a provocações femininas ou urgência biológica incontrolável, nem em um espaço social aberrante. Tudo isso são explicações produzidas para desviar o tema de seus verdadeiros propósitos. Ao contrário, o estupro é a mais direta expressão de política sexual, trata-se antes de mais nada de um ato de conformidade com as normas da masculinidade e uma forma terrível de terrorismo a serviço da preservação do status quo na arena da luta de gêneros. É preciso frisar bem e dar bastante visibilidade a esse discurso da violência a serviço de um gênero. Como o estupro, o assassinato de mulheres por seus maridos, pais, amantes, conhecidos e estranhos não podem ser produtos de um inexplicável desvio de comportamento. Todos eles são feminicidas, a mais extrema forma de terrorismo sexista, motivada por ódio, desprezo, prazer ou por um senso de propriedade sobre as mulheres, afirmam Caputi e Russell (1992).

Esse palco de horrores tem suas fronteiras muito bem estabelecidas e muito bem conhecidas. O feminicídio inclui assassinato com mutilação ou antecedido por estupro, além de uma escalada de agressões físicas que culmina na morte da mulher. Também podem ser vistos como feminicídios, conforme o pensamento de Caputi e Russell (1992), a imolação de mulheres acusadas de bruxaria na Europa Ocidental, de noivas e viúvas na Î́ndia, os crimes de honra em países latinos e do Oriente Médio, onde mulheres que perdem ou se acredita terem perdido a virgindade são mortas por seus parentes masculinos. $\mathrm{O}$ fato de chamarem de feminicidas os assassinos misóginos retira o véu que cobre os crimes de gênero no mundo, em qualquer parte, bem mais visível do que homicídio ou assassinato, no que tange a sua representação e a sua motivação.

A generalizada identificação com a visão masculina de mundo apenas mostra o quão enraizada é a cultura sexista na qual nós vivemos. Caputi e Russell (1992) citam como exemplo a acolhida à estudante de engenharia Celeste Brousseau, na Universidade de Alberta, quando atuou contra a cultura sexista. Seus colegas gritavam contra ela um coro de Shoot the bitch (Atire na prostituta) quando ela participou de um ato logo após os assassinatos de Lépine, em Montreal.

Cenas como esta revelam que a misoginia não apenas motiva a violência contra as mulheres, mas também distorce a cobertura da imprensa sobre crimes dessa natureza. Para Caputi e Russell (1992), feminicídios, estupros e agressões são geralmente ignorados ou recebem uma cobertura sensacionalista da mídia, dependendo da raça, da classe social e da aparência física das vítimas, segundo os padrões masculinos. A polícia, a mídia e o público respondem aos crimes contra mulheres de cor, mulheres pobres, lésbicas, prostitutas e usuárias de drogas de maneira abismal, com profunda apatia atada a estereótipos pejorativos e normalmente culpando a vítima. Segundo essa visão, pessoas negras são sempre usuárias de drogas e as prostitutas sempre colocam os homens em grave risco, razão por que terminam sendo alvo de agressões e mortes.

Nem sempre, contudo, pode se imaginar o feminicídio como um ato único, visível, particularmente afeto a uma violência de momento. $\mathrm{O}$ que ocorre antes e durante o crime deve ser levado em conta: 
O feminicídio é o término, o fim extremo de um continuum de terror contra as mulheres que inclui uma vasta gama de ações, que vão muito além de abusos verbais e físicos, tais como estupro, tortura, escravidão sexual (particularmente a prostituição), incesto e abuso sexual na infância, agressões físicas e emocionais, assédio sexual (no telefone, nas ruas, no escritório em salas de aula), mutilações genitais (clitoridectomia, excisão, infibulação), operações ginecológicas desnecessárias (histerectomia gratuita), heterossexualidade forçada, esterilização contra a vontade, maternidade forçada pela criminalização do aborto e da contracepção, psicocirurgia, negação de alimentos a mulheres em algumas culturas, cirurgias cosméticas e outras mutilações em nome da estética. Quando essas formas de terrorismo terminam em morte, tem-se o feminicídio. (CAPUTI; RUSSELL, 1992, p. 15, tradução nossa) ${ }^{1}$.

Portanto, o crime, se ele se concretiza na forma terminal do assassinato, por outro lado, envolve toda uma gama de agressões antes e durante um lapso de tempo, razão pela qual todo ele deve ser levado em conta nas políticas públicas de combate à violência contra a mulher, por meio de ações concretas visíveis e marcantes, como também por meio de informação, mudança de culturas e combate aos estereótipos de um status quo masculino de gênero.

Ocorrem no mundo acontecimentos que rememoram eventos passados de violência contra a mulher. Caputi e Russell (1992) afirmam que tais comemorações são efeitos paliativos e não a cura. Feministas, de forma coletiva e internacionalmente, têm uma tarefa urgente de montar estratégias contra o feminicídio. Fezse durante anos um boicote contra a violência do apartheid na África do Sul. Por que não um boicote contra a violência contra as mulheres, perguntam as autoras. Elas lembram que numa peça famosa de Aristófanes, chamada Lisistrata, as mulheres fizeram com sucesso um boicote contra os homens, que não teriam mais sexo enquanto não terminassem com as guerras. Lembram a repetição de um boicote entre as mulheres iroquesas contra a guerra entra as nações. "Agora, demandamos um fim à guerra patriarcal contra as mulheres no mundo", postulam Caputi e Russell (1992, p. 21, tradução nossa)².

Vivemos numa cultura feminicida. Para as autoras, essa forma de cultura é aquela na qual o homem é adorado. Essa adoração provém graças à tirania, seja ela sutil ou aberta. Ela marcha sobre as mentes esmagadas das mulheres, sobre seus corpos mortos, machucados ou odiados, vivendo sob uma cooptação constante, vinda de estupradores, agressores e assassinos. Num último apelo, as autoras clamam: deixe-nos retirar nossa adoração sem sermos mortas por isso.

\section{Dualidade das noções de sexo e gênero e suas consequências}

A questão de gênero e sua multiplicidade é uma construção cultural. No caso da mulher, a tensão é ainda maior, pelo fato de ela não nascer mulher, mas tornar-se uma, através dos próprios efeitos civilizatórios. No princípio mesmo assemelha-se ao homem, ou melhor, ao menino, em sua robustez, até os 12 anos de idade. Fazer-se mulher faz parte da construção humana desse ser castrado em sua evolução rumo a uma identidade:

Ninguém nasce mulher: torna-se mulher. Nenhum destino biológico, psíquico, econômico define a forma que a fêmea humana assume no seio da sociedade; é o conjunto da civilização que elabora esse produto intermediário entre o macho e o castrado que qualificam de feminino. Somente a mediação de outrem pode constituir um indivíduo como um Outro. Enquanto existe para si, a criança não pode apreender-se como sexualmente diferençada. Entre meninas e meninos, o corpo é, primeiramente, a irradiação de uma subjetividade, o instrumento que efetua a compreensão do mundo: é através dos olhos, das mãos e não das partes sexuais que apreendem o universo. O drama do nascimento, o da desmama desenvolvem-se da mesma maneira para as crianças dos dois sexos; têm elas os mesmos interesses, os mesmos prazeres; a sucção é, inicialmente, a fonte de suas sensações mais agradáveis; passam depois por uma fase anal em que tiram, das funções excretórias que lhe são comuns, as maiores satisfações; seu desenvolvimento genital é análogo; exploram o corpo com a mesma curiosidade e a mesma indiferença; do clitóris e do pênis tiram o mesmo prazer incerto; na medida em que já se objetiva sua sensibilidade, voltam-se para a mãe: é a carne feminina, suave, lisa, elástica que suscita desejos sexuais e esses desejos são preensivos; é de uma maneira agressiva que a menina, como o menino, beija a mãe, acaricia-a, apalpa-a; têm o mesmo ciúme se nasce outra criança; manifestam-no da mesma maneira: cólera, emburramento, distúrbios urinários; recorrem aos mesmos ardis para captar o amor dos adultos. (BEAUVOIR, 1967, p. 9).

Esta longa citação atribui um sentido à afirmação de que as crianças, sejam meninas, sejam meninos, são semelhantes na apreensão do mundo, enquanto existem para si. Somente a evolução civilizatória, com suas 
normas e distribuições de papéis, é que fará a diferenciação, dando à mulher um lugar já previamente reservado. Sua passividade, se se tornam traços que advêm desde os primeiros anos, não significa que seja um dado biológico. O esforço do menino em sua liberdade e força faz com que despreze as meninas e a sociedade cuida do resto para colocá-las em seu devido espaço em uma passividade arranjada culturalmente. Recusam-lhe a mesma liberdade dada aos meninos, aos homens. Para agradar precisa fazer-se uma boneca viva, fazer-se objeto. Sem encorajamento, não busca compreender o mundo como sujeito. Não há, portanto, destino biológico, a definição do sexo por natureza para proporcionar o gênero. $\mathrm{O}$ conjunto dos meios civilizatórios que dão maior liberdade e força aos homens é que elabora o produto final desse ser intermediário entre o macho e o castrado, que vai receber a denominação de feminino.

Para opor-se à suposta fatalidade do sexo dado pela natureza e suas dimensões de passividade e superioridade, Scott (1990) constrói o conceito de gênero para definir relações de poder, desatando-os da dimensão natural e atando-os à dimensão cultural, de construção a partir de um ponto de vista único de quem tem status quo em termos de gênero. Ou seja, gênero explicita melhor as condições efetuadas pelo binarismo de que o sexo impõe com seu reducionismo naturalizante. Assim, o gênero é socialmente construído, enquanto o sexo é biologicamente dado, aquele tomando proporções culturais.

Toneli (2012) expõe posições diversas sobre o gênero, o que já começa a criar contestações em termos do binarismo provocado pela própria oposição entre sexo/gênero. Em primeiro lugar, existe uma diferença múltipla entre as mulheres e não binária entre homem/mulher. Em segundo lugar, o gênero é performático e múltiplo, sem ser identidade ou totalidade. Assim, o sexo não estaria para a natureza enquanto o gênero estaria para a cultura, mas trata-se de um discurso de instauração dos corpos e do sexo. Isso permite pensar a sexualidade como uma construção social e histórica que se relaciona sempre com a disposição do poder na sociedade. Nesse contexto, a própria Beauvoir (1967) é questionada, assim como as feministas que puseram em prática o conceito de gênero.

A necessidade de rediscussão da noção de gênero veio com o contraste entre a ideia de identidade comum da mulher e a oposição binária gênero/sexo. Para Butler (2003), no início essa oposição foi criada para questionar a formulação de que a biologia é uma questão de destino. No entanto, o gênero acabou não sendo resultado causal do sexo nem tampouco fixo como ele. Ao estabelecer o conceito de gênero insurgiu-se contra a unidade do sujeito abrindo espaço para uma interpretação múltipla do sexo. A partir daí, Butler abre uma série de questionamentos sobre a existência do gênero, mas sem inutilizar por completo a noção. Aliás, o próprio questionamento leva à certeza ontológica do termo. Sua existência, enfim, estaria mais na multiplicidade do que propriamente na oposição binária homem/mulher, já que um mesmo sexo, sendo homem, pode se traduzir em determinadas culturas a posição de marido ou de esposa. Em princípio, as feministas deveriam primeiro discutir a existência do sexo e sua possível construção cultural, como atestam os inúmeros discursos científicos que o constroem para nós. Ao mesmo tempo, devem também questionar a noção de gênero e os mecanismos dessa construção.

Ao envolver a discussão do gênero como construção cultural, Butler (2003) inverte as polarizações, concluindo que em vez da biologia ser o destino, no que diz respeito ao sexo, no segundo caso, o determinismo passa a ser a cultura, ou seja, ela é o destino. Livre-arbítrio e determinismo parecem comandar essa discussão entre a fixidade e a liberdade dos termos quando se trata do binarismo natureza/cultura:

A controvérsia sobre o significado de construção parece basear-se na polaridade filosófica convencional entre livre-arbítrio e determinismo. Em consequência, seria razoável suspeitar que algumas restrições linguísticas comuns ao pensamento tanto formam como limitam os termos do debate. Nos limites desses termos, o "corpo" aparece como um meio passivo sobre o qual se inscrevem significados culturais, ou então como instrumento pelo qual uma vontade de apropriação ou de interpretação determina o significado cultural por si mesma. Em ambos os casos, o corpo é representado como um mero instrumento ou meio com o qual um conjunto de significados culturais é apenas externamente relacionado. Mas o "corpo" é em si mesmo uma construção, assim como o é a miríade de "corpos" que constitui o domínio dos sujeitos com marcas de gênero. Não se pode dizer que os corpos tenham uma existência significável anterior à marca do seu gênero; e emerge então questão: em que medida pode o corpo vir a existir na(s) marca(s) do gênero e por meio delas? (BUTLER, 2003, p. 27, grifo da autora).

Como o leitor pode ver, a autora não descarta nem um nem outro, mas não deixa de indicar a complexidade da questão visto que tanto sexo, gênero e corpo são existências culturais, sobre os quais incidem mais questões do que respostas. Dentre a polaridade filosófica que norteia o debate, o corpo estaria numa posição de passividade sobre quem a cultura viria estabelecer noções, ações e uma eticidade provocadora. Neste caso, uma vontade incidiria sobre ele e determinaria um significado cultural externo, com um sentido em si mesmo, sem outras utilidades que a mera nomeação, sem levar em conta que o corpo é ele mesmo uma construção. 
Seria um paradoxo dizer que o corpo ou a miríade de corpos que constitui o domínio dos sujeitos com marcas de gênero, poderia ter existência significável anterior à marca de gênero. É preciso conceber o corpo novamente não mais como um meio ou instrumento à espera de uma vontade que o vivifique de forma imaterial. Para Butler (2003), afinal de contas, se o gênero e o sexo são fixos ou livre, tudo não passa de um discurso que estabeleça limites ou a salvaguarda de um humanismo como pressuposto à análise de gênero. Discurso com limites de uma experiência condicionada, nas fronteiras de um discurso hegemônico, "baseado em estruturas binárias que se apresentam como a linguagem da racionalidade universal. Assim, a coerção é introduzida naquilo que a linguagem constitui como o domínio imaginável do gênero". (BUTLER, 2003, p. 28).

No Brasil, as autoridades oscilam entre os dois eixos, o da fixação e o da liberdade no uso dos conceitos, ora voltando-se para o sexo como elemento dado, mas culturalmente questionado, como expõem as conclusões acima, ora voltando-se para o gênero, em suas relações de poder sob o domínio do homem. O governo federal, ao demarcar diretrizes nacionais contra o feminicídio, observa as razões de gênero no combate à violência contra a mulher:

As Diretrizes Nacionais visam colaborar para o aprimoramento da investigação policial, do processo judicial e do julgamento das mortes violentas de mulheres de modo a evidenciar as razões de gênero como causas dessas mortes. O objetivo é reconhecer que, em contextos e circunstâncias particulares, as desigualdades de poder estruturantes das relações de gênero contribuem para aumentar a vulnerabilidade e o risco que resultam nessas mortes e, a partir disso, aprimorar a resposta do Estado, em conformidade com as obrigações nacionais e internacionais assumidas pelo governo brasileiro. (BRASIL, 2016, p. 16, grifo nosso).

Já a Lei no 13.104, de 9 de março de 2015, a Lei do Feminicídio, mostrou preferência pela inclusão de diferença de sexo, conforme informa o inciso VI do artigo 121 do Código Penal, de acordo com a nova redação para homicídio, a fim de incluir a nova tipificação. A lei fala de crimes "contra a mulher por razões de sexo feminino", e define essas razões quando o crime envolve violência doméstica e familiar e menosprezo ou discriminação à condição de mulher (BRASIL, 2015). Como se vê, além de evitar um termo cunhado pela própria instituição feminista, a lei ficou aquém do continuum de violência contra a mulher, no espaço de tempo que antecede o assassinato de mulheres.

\section{Considerações finais}

Uma dupla nomeação do crime de assassinato de mulheres por razões de gênero teve curso na América Latina e no Brasil. Denominaram femicídio e feminicídio a esse tipo de crime, com a diferença de que no segundo, feminicídio, há uma marca indelével de omissão do Estado na perpetração dos crimes e no seu combate. Em inglês, outros nomes surgem com ampliações de seu alcance, como femicide e gendercide. Para o segundo, haveria pré-seleção do gênero por meio de práticas e técnicas em países, especialmente da Ásia. Por outro lado, femicide corresponde a um continuum de violência que vai desde as mais simples agressões e assédios a violências agudas e recorrentes que, quando culminam em morte, ocorre o feminicídio.

Ainda assim, o questionamento sobre a determinação do sexo biológico em oposição ao gênero, como supremacia de poder masculino, culturalmente construído, cunhado pelas feministas, destaca-se em estudos contemporâneos. O que escolher depende de um posicionamento discursivo, ele próprio cultural e empoderativo. No Brasil, os poderes executivo e legislativo divergem quanto à escolha. O executivo prefere a noção de gênero, enquanto o legislativo optou, por uma suposta neutralidade da justiça, por diferença de sexo. A divergência mostra fragilidade no combate à violência contra a mulher, dentre eles a mais extrema forma que é o feminicídio. O certo é a escolha de combate a esse crime por razões de gênero, por ser uma noção cunhada pelas próprias mulheres, que traz o benefício de seu empoderamento, além, é claro, de incluir na lei o combate ao continuum de violência que culmina no feminicídio.

\section{Referências}

ALBA, A. G. de; GÚZMAN, G. Feminicidio: the "black legend" of the border. In: (Ed.). Making a killing: femicide, free trade, and la frontera. Austin: University of Texas Press, 2010. p. 1-21.

BANDELI, D. Femicide, gender \& violence: discourses and counterdiscourses in Italy. Brisbane: Palgrave Macmillan, 2017.

BEAUVOIR, S. de. O segundo sexo: a experiência vivida. 2. ed. São Paulo: Difusão Europeia do Livro, 1967.

BRASIL. Lei no 13.104, de 9 de março de 2015. Altera o art. 121 do Decreto-Lei n ${ }^{\circ}$ 2.848, de 7 de dezembro de 1940 - Código Penal, para prever o feminicídio como circunstância qualificadora do crime de homicídio, e o art. $1^{\circ}$ da Lei no 8.072 , de 25 de julho de 1990 , para 
incluir o feminicídio no rol dos crimes hediondos. Diário Oficial da União, Brasília, DF, 10 mar. 2015. Disponível em: <http:// www.planalto.gov.br/ccivil_03/_Ato2015-2018/2015/lei/L13104.htm>. Acesso em: 4 jan. 2018.

. Secretaria de Políticas para Mulheres. Diretrizes Nacionais para investigar, processar e julgar com perspectiva de gênero as mortes violentas de mulheres (feminicídios). Brasília, DF, 2016. Disponível em: <http://www.spm.gov.br/central-de-conteudos/ publicacoes/2016/livro-diretrizes-nacionais-femenicidios-versao-web.pdf $>$. Acesso em: 04 jan. 2018.

BUTLER, J. Problemas de gênero: feminismo e subversão da identidade. Rio de Janeiro: Civilização Brasileira, 2003.

CAPUTI, J.; RUSSELL, D. E. H. Femicide: sexist terrorism against women. In: RADFORD, J.; RUSSELL, D. E. H. (Ed.). Femicide: the politics of woman killing. New York: Twaine Publishers, 1992. p. 13-24.

GEBRIM, L. M.; BORGES, P. C. C. Violência de gênero: tipificar ou não o femicídio/feminicídio? Revista de Informação Legislativa, Brasília, ano 51, n. 202, p. 59-75, abr.jun. 2014. Disponível em: <https://www12.senado.leg.br/ril/edicoes/51/202/ril_v51_n202_p59.pdf>. Acesso em: 07 dez. 2017.

GRECH, V.; MAMO, J. Gendercide: a review of the missing women. Malta Medical Journal, Msida, v. 26, n. 1, p. 8-11, 2014. Disponível em: <http://www.um.edu.mt/umms/mmj/PDF/418.pdf>. Acesso em: 05 dez. 2017.

LAGARDE, M. Del femicidio al feminicidio. Revista de Psicoanálisis, Bogotá, n. 6, p. 216-225, 2006. Disponível em: <https:// revistas.unal.edu.co/index.php/jardin/article/view/8343>. Acesso em: 07 dez. 2017.

. Preface: Feminist keys for understanding feminicide: theoretical, political an legal construction. In: FREGOSO, R. L.; BEJARANO, C. (Ed.). Terrorizing women: feminicide in the Americas. Durham: Duke University Press, 2010. p. xi-xxvii.

MENEGHEL, S. N.; PORTELLA, A. P. Feminicídios: conceitos, tipos, cenários. Ciência \& Saúde Coletiva, Rio de Janeiro, v. 22 , n. 9, p. 3077-3086, set. 2017. Disponível em: <http://www.scielo.br/pdf/csc/v22n9/1413-8123-csc-22-09-3077.pdf>. Acesso em: 15 dez. 2017.

MYERS, C. Sex selective abortion in India. Global Tides, Washington, D.C., v. 6, p. 1-18, 2012. Disponível em: <https:// digitalcommons.pepperdine.edu/globaltides/vol6/iss1/3/>. Acesso em: 07 dez. 2017.

SAGOT, M.; CABAÑAS, A. C. When violence against women kills: femicide in Costa Rica, 1990-99. In: FREGOSO, R. L.; BEJARANO, C. (Ed.). Terrorizing women: feminicide in the Americas. Durham: Duke University Press, 2010. p. 138-156.

SCOTT, J. Gênero: uma categoria útil de análise histórica. Educação e Realidade, Porto Alegre, v. 15, n. 2, p. 5-22, 1990.

TONELI, M. J. F. Sexualidade, gênero e gerações: continuando o debate. In: JACÓ-VILELA, A. M.; SATO, L. (Org.). Diálogos em psicologia social. Rio de Janeiro: Centro Edelstein de Pesquisas Sociais, 2012. p. 147-167. Disponível em: <http://books.scielo.org/id/ vfgfh/pdf/jaco-9788579820601-12.pdf $>$. Acesso em: 03 jan. 2018.

WARREN, M. A. Gendercide: the implications of sex selection. Totowa: Rowman \& Allanheld, 1985.

\section{Notas}

1 "Femicide is on the extreme end of continuum of antifemale terror that includes a wide variety of verbal and physical abuse, such as rape, torture, sexual slavery (particularly in prostitution), incestuous and extrafamilial child sexual abuse, physical and emotional battery, sexual harassment(on the phone, in the streets, at the office, and in the classroom), genital mutilation (clitoridectomies, excision, infibulations), unnecessary gynecological operations (gratuitous hysterectomies), forced heterosexuality, forced sterilization, forced motherhood (by criminalizing contraception and abortion), psychosurgery, denial of food to women in some cultures, cosmetic surgery, and other mutilations in the name of beautification. Whenever these forms of terrorism result in death, they become femicides." (CAPUTI; RUSSELL, 1992, p. 15).

2 "We must now demand an end to the global patriarchal war on women." (CAPUTI; RUSSELL, 1992, p. 21).

\section{Suzanny Mara Jobim de Souza}

jobimmelo@hotmail.com

Especialização em Didática e Metodologia de Ensino Superior pela Universidade Estadual de Montes Claros (UNIMONTES)

Pesquisadora do Grupo de Estudos e Pesquisa em Raça/Etnia, Política Social e Família na Universidade Federal da Bahia (UFBA)

\section{UFBA}

Instituto de Psicologia

Estrada de São Lázaro, 197 - Federação

Salvador - Bahia - Brasil

CEP: $40.210-730$ 
Agência financiadora

Não se aplica.

Contribuições dos autores

Não se aplica.

Aprovação por Comitê de Ética e consentimento para participação

Não se aplica.
Consentimento para publicação

Não se aplica.

Conflito de interesses

Não há conflito de interesses. 